\title{
Addressing Academic Integrity in Education and Innovation
}

\author{
Murali Krishnamurthi and Jason Rhode
}

\begin{abstract}
Globalization has given rise to new opportunities for innovation in education and technology. However, globalization has also exacerbated some of the challenges related to integrity in the creation, sharing and consumption of information by a worldwide community of educators, students, institutions, and society, as a whole. Concerns of integrity have a broader impact ranging from personal to global markets for goods and services. Academic institutions have been exploring ways to engage faculty in developing new tools and techniques to promote academic integrity in education and innovation. In this paper, the efforts of one institution to provide faculty with tools to promote academic integrity in teaching and learning, results and lessons learned from that experience, and recommendations for how others can extend these ideas to address academic integrity in education and innovation will be discussed.
\end{abstract}

Index Terms-Academic integrity, cheating, online, plagiarism, tutorial.

\section{INTRODUCTION}

The globalization of education and technology has given rise to new opportunities for innovation along with new challenges for educators, institutions, businesses, and society as a whole. While academic integrity has been a concern for educators over thousands of years [1], the rise of internet technologies has made it easy for those willing to plagiarize, cheat, steal intellectual property, and conduct corporate espionage [2]. There have been a number of studies documenting the increase in academic dishonesty [3]-[5] and numerous research articles summarizing the causes and consequences of academic dishonesty [6], [7] and the possible relationship between academic dishonesty and employment-related dishonesty [8], [9]. What is clear from the documented studies and research articles is the daunting task educators, institutions, and employers face in addressing the issue.

The perspectives on academic integrity vary among students, educators, institutions, and employers, and that is not necessarily surprising. What one population thinks as

Manuscript received December 9, 2017; revised May 24, 2018. This work was supported in part by the Northern Illinois University (NIU) Committee for the Improvement of Undergraduate Education under the Project for Improvement of Undergraduate Education grant, the NIU Faculty Development and Instructional Design Center, the NIU Office of the Ombudsperson, and NIU University Writing Center.

M. Krishnamurthi is with the Department of Industrial and Systems Engineering, Northern Illinois University, DeKalb, IL 60115 USA (e-mail: mkrishna@niu.edu).

J. Rhode is with the Department of Educational Technology, Research and Assessment, Northern Illinois University, DeKalb, IL 60115 USA (e-mail: jrhode@niu.edu). dishonesty, the other population may view it as convenience or even engage in it out of ignorance, however indefensible it may be or as a mode of survival. For example, corporate espionage and stealing of trade secrets have grown in alarming proportions in recent years and some businesses and even some countries engage in economic espionage to gain an upper hand in the global economy, thus costing economies trillions of dollars and millions of jobs a year [10]. Even though many countries are working out complex legal agreements to prevent cyber theft of intellectual property, enforcing such legal agreements is difficult and often not timely to protect businesses and their economic bottom line. Along with such laws and their enforcement, there is a need for educating the society on the moral and ethical issues related to academic dishonesty so that innovations can flourish and everyone can thrive.

Institutions, both academic as well as industry, have a role in addressing integrity issues although their perspectives and efforts may vary. The 2002 Arthur Andersen and Enron scandal and their collapse [11] was a wakeup call for many businesses in U.S., and a number of them have since instituted ethics training and protocols for their employees. Lack of ethics and integrity impact their bottom line and academic institutions continue to develop and promote honor codes and academic integrity training, establish offices of student conduct, and enforce policies and procedures to promote academic integrity. Some institutions have gone to the extent of developing or licensing tools to check students' work for plagiarism, thus adding to the cost of education. Some countries have also established forums across continents to stem the tide of academic dishonesty [12]. Internet technologies, however, have made it challenging to keep up with the new ways one can cheat, plagiarize, and use paid services to complete academic work. This does not mean institutions can or want to give up addressing integrity but it is even more important that institutions engage faculty, students, and all employees in promoting academic integrity.

Faculty are often on the front lines of educating students on academic integrity as well as dealing with incidents of academic dishonesty among students as well as potential for plagiarism in their own scholarly work. Their perspectives on this issue are worth noting. The increase in the use of hand-held devices, smart technologies, and online courses have made it challenging for them to dedicate their time to promote academic integrity as well as police students on academic dishonesty incidents. They have to keep up with new technologies and new ways students use technologies to cheat and plagiarize. However, faculty do realize their prominent role in educating students on moral and ethical issues related to academic dishonesty and the long term impact it can have on students' self-esteem, employment, and 
the society.

Students' perspectives on academic integrity also require consideration as they give a window into their world on why some students cheat and plagiarize and why some do not. There are a number of reasons as to why students cheat and plagiarize, including their inability to manage demands of student life, peer pressure, faculty inattention to students' performance, unclear course policies, performance anxiety, and lack of understanding of the consequences of academic dishonesty [6]. Student academic dishonesty also varies by discipline and demographics, and research has shown there is more cheating in professional disciplines such as medicine, business, law and engineering due to competition and peer pressure compared to humanities and social sciences [13]. International students also have unique perspectives on academic dishonesty as norms of intellectual property can vary among cultures and non-native language speakers' way of learning in a new culture and language setting may also lead to students' misunderstanding on academic integrity [14], [15].

Regardless of the perspectives, there is a need for educating students on academic integrity, and one of the ways institutions have addressed this need is through educational tutorials. A number of higher education institutions have developed and made available online tutorials to promote academic integrity and these tutorials vary from simple websites to engaging self-paced tutorials. In the following sections, the implementation and testing of one such tutorial is discussed along with analysis of results and lessons learned.

\section{TUTORIAL ON ACADEMIC INTEGRITY}

At Northern Illinois University, academic integrity has been addressed in many ways including statements on academic integrity in the undergraduate and graduate catalogs and course syllabi, faculty reinforcing academic integrity in their courses, the use of plagiarism detection tools such as SafeAssign [16] in Blackboard web course management system to screen students' work, and faculty monitoring students' work closely. Along with these important efforts, the need for educating students on academic integrity was recognized, and an online tutorial on academic integrity for students was initially designed, developed and implemented with input from faculty, students Office of Student Conduct, and the Office of the Ombudsperson at the university.

The input clearly indicated that the tutorial should be engaging and easy to use on any platform without logins and passwords and without saving data on users. The objectives of the tutorial were to: (1) increase students' awareness of academic integrity issues, (2) offer students strategies to prevent academic dishonesty situations and protect themselves, and (3) for faculty to use the tutorial to supplement classroom discussions on academic integrity. The authors reviewed the existing literature on academic integrity, interviewed faculty and staff at Northern Illinois University, and developed an online tutorial that included content, quizzes, games, and offered a certificate of completion.
The student tutorial was used in three courses at Northern Illinois University and a preliminary test was conducted with a group of 55 students. The details of the initial student tutorial and the preliminary results were published by the authors [17]. The preliminary results indicated that the student tutorial was effective but the games were not engaging and unnecessary, and that the sophisticated technologies used to design the tutorial would make it difficult to update it in the future. It was recognized that the faculty also needed a tutorial to offer them insights on why and how students committed academic dishonesty, how to prevent students from commit academic dishonesty, how faculty can design effective course activities and exams to promote academic integrity, and what they could do to address academic dishonesty incidents. As a result, a faculty tutorial was also designed along with redesign of the student tutorial, and both the student and faculty tutorials were implemented in one site at http://www.niu.edu/academic-integrity. Fig. 1 shows the main page of the tutorial website, and Table I lists the topics covered in the student and faculty tutorials.

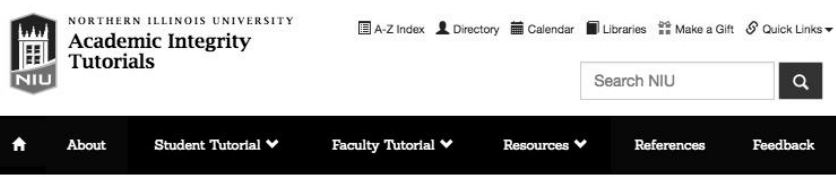

Academic Integrity Tutorials

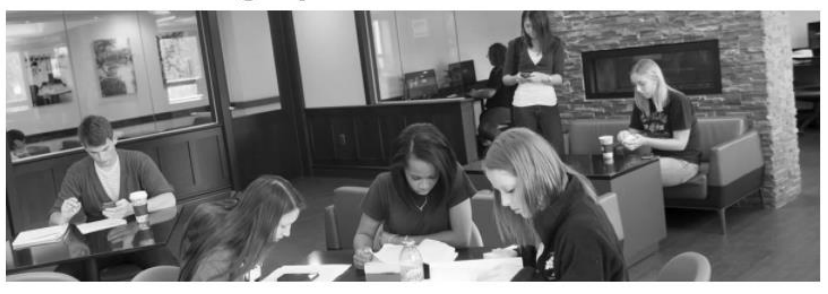

The purpose of these tutorials is to promote academic integrity at Northern Illinois University by increasing students' awareness of the issues, offering strategies for students to protect themselves from academic dishonesty situations, and increasing faculty's awareness of the issues and offering them strategies to address academic dishonesty incidents effectively. These tutorials are intended for self-paced learning by students and faculty and can be used as an educational resource to supplement classroom discussions on academic integrity.

\section{Start the Student Tutorial}

Start the Faculty Tutorial

Fig. 1. Main page of the student and faculty tutorials.

TABLE I: TOPICS COVERED IN STUDENT AND FACULTY TUTORIALS

\begin{tabular}{ll}
\hline \hline Student Tutorial Topics & Faculty Tutorial Topics \\
\hline Definition and types & Definition and types \\
Causes & Causes \\
Consequences & Consequences \\
Plagiarism & How students commit academic \\
Cheating, falsification, fabrication & dishonesty \\
and sabotage & academic dishonesty by students \\
Protecting yourself & Designing effective course \\
& assessments \\
& Conducting exams \\
& Addressing incidents
\end{tabular}

As the tutorial was intended to be viewed online, the content was organized into easily readable short paragraphs and bullets that users could read quickly on the screen. The focus of the content was to explain academic integrity and related issues, offer tips on how to avoid cheating and plagiarism, and protect oneself from accusations of cheating 
and plagiarism but not to preach virtues of academic integrity or possible penalties for academic dishonesty. Each screen of the content was designed to include clickable graphics with answers to engage tutorial users. Content screens were designed to include navigation buttons at the bottom of the screens and table of contents on the left to allow users go from one topic to the next or directly go to a particular topic of the tutorial. Fig. 2 shows a sample screen capture of the content design screen.
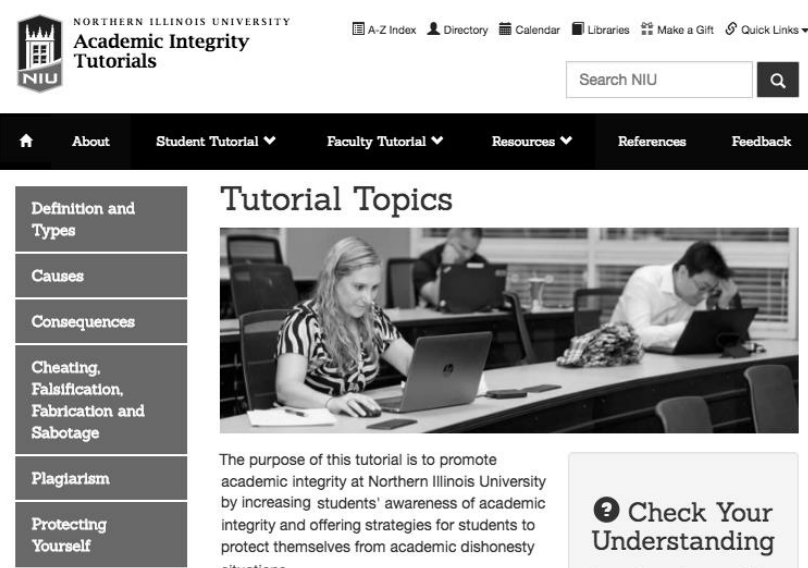

The purpose of this tutorial is to promote academic integrity at Northern Illinois University by increasing students' awareness of academic integrity and offering strategies for students to protect themselves from academic dishonest

The content of this tutorial is organized under the following six major sections:

- Definition and Types

Causes for Academic Dishonesty

- Consequences of Academic Dishonesty

Cheating, Fabrication, Falsification and

Sabotage

- Plagiarism

Fig. 2. Screenshot of a main page of the student and faculty tutorials.

To engage users and to help them self-test their comprehension of topics, both the student and faculty tutorials were designed to include quizzes at the end of each topic. The student tutorial includes six quizzes, and the faculty tutorial includes eight quizzes as well as six case scenarios at the end. The quiz questions are either multiple choice or true/false type, and after completing $70 \%$ of the quizzes correctly, users of the student tutorial can print a Certificate of Completion. Fig. 3 shows a sample screen of a quiz question from the student tutorial and Figure 4 shows a sample screen of the certificate of completion.
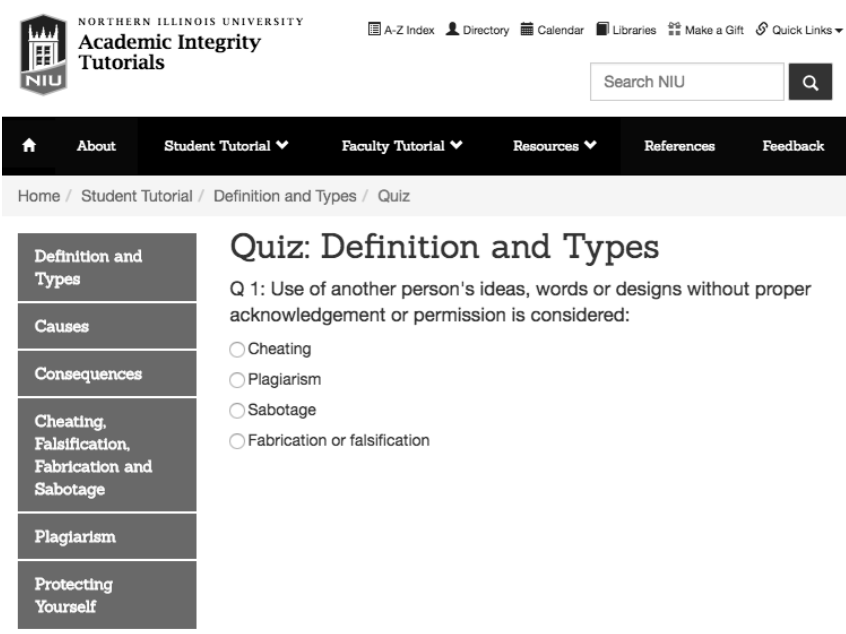

Fig. 3. Screenshot of a tutorial question.

The six case scenarios included at the end of the faculty tutorial were contributed by the University Ombudsperson from his actual experience handling those scenarios. The cases scenarios were designed as decision-trees to help faculty users explore the possibilities that they might encounter in their classes and view the consequences of a particular course action. Fig. 5 shows a sample screen of a case scenario.

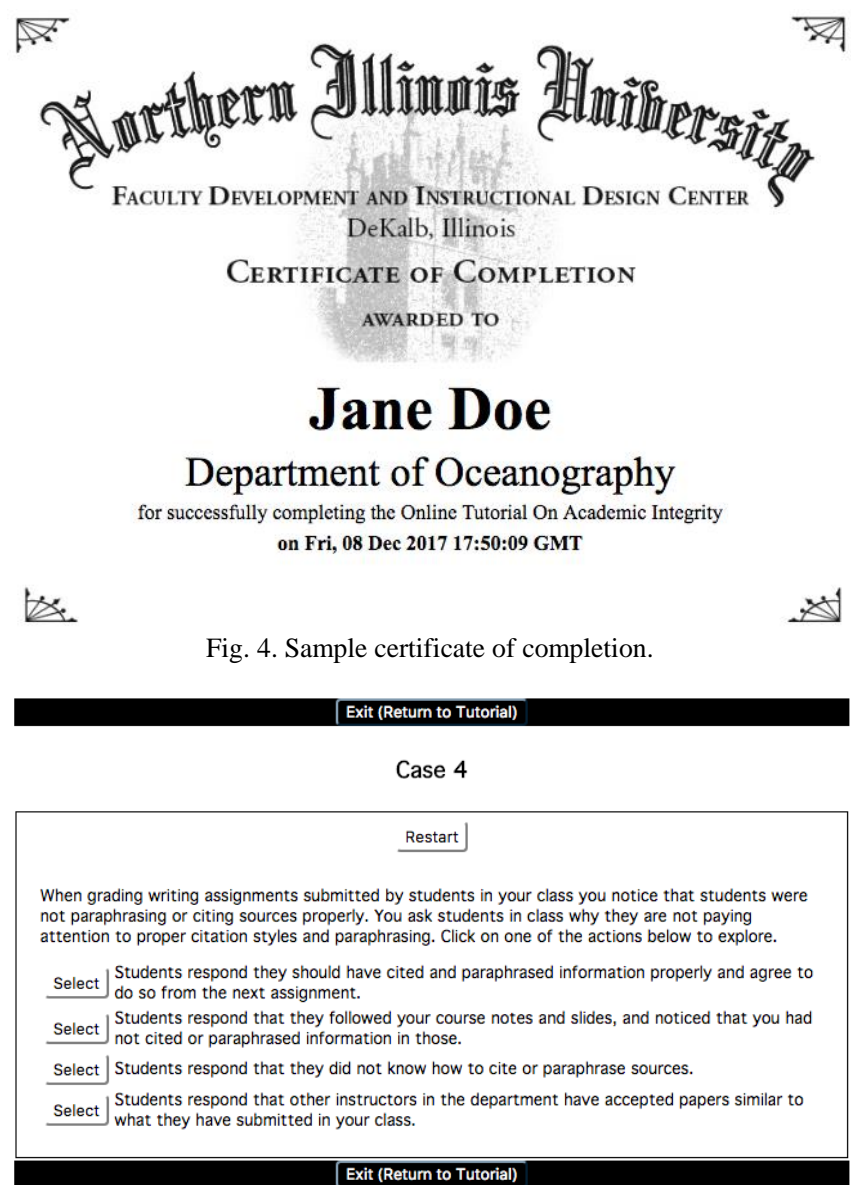

Fig. 5. Screenshot of a case scenario in the faculty tutorial.

For ease of modification in the future, for accommodating those with disabilities and to be usable in any platform whether a computer or a mobile device, the tutorial content, quizzes, and case scenarios have been implemented using basic HTML and JavaScript. Navigation within a topic and between topics have been designed to be consistent and simple. Each tutorial is designed to be viewable within 30 minutes and the quizzes and case scenarios may take another 15 minutes, depending on individual user's interaction with the tutorial.

\section{TUtORIAL TESTING AND ANALYSIS}

Along with designing and implementing educational tutorials, it is necessary to test if a tutorial has the intended impact on the potential audience. As mentioned earlier, a test of the initially developed student tutorial was conducted with 55 students, which indicated that some portions of the tutorial required more clarity and the test questions themselves needed some revision. Based on the feedback from the preliminary test, the student tutorial was completely revised, and a faculty tutorial was also included along with it on the same website. A pre and post-test of the revised student 
tutorial was conducted with 72 students enrolled in 4 different courses at the university, and the results were analyzed to assess the effectiveness of the tutorial. The pre and post-tests included 15 questions out of which 14 of them were on the six topics covered in the student tutorial. The 15 th question required students to self-assess themselves on various academic integrity issues before and after going through the tutorial. A simple comparison of percentage of students who correctly answered the 14 questions in the pre and post-tests indicated that students' comprehension of academic integrity issues was better overall after going through the tutorial, and the results from the revised tutorial were clearly better compared to those from the preliminary test of the earlier version of the tutorial. This can be easily seen from the data presented in Table 2. The self-assessment scores by students for the 15th question (not shown in the table) were obviously higher in the post-test compared to the pre-test. This was anticipated as students were asked to rate themselves on their comprehension of academic integrity issues before and after reviewing the tutorial.

TABLE II: COMPARISON OF PERCENTAGE OF CORRECT RESPONSES BY STUDENTS IN PRE AND POST-TESTS

\begin{tabular}{|c|c|c|c|c|c|c|c|c|c|c|c|c|c|c|}
\hline Question & 1 & 2 & 3 & 4 & 5 & 6 & 7 & 8 & 9 & 10 & 11 & 12 & 13 & 14 \\
\hline $\begin{array}{l}\text { Pre-Test } \\
\mathrm{n}=72\end{array}$ & $90 \%$ & $83 \%$ & $96 \%$ & $50 \%$ & $76 \%$ & $99 \%$ & $92 \%$ & $100 \%$ & $85 \%$ & $100 \%$ & $85 \%$ & $75 \%$ & $88 \%$ & $58 \%$ \\
\hline $\begin{array}{l}\text { Post-Test } \\
n=72\end{array}$ & $99 \%$ & $96 \%$ & $100 \%$ & $81 \%$ & $89 \%$ & $99 \%$ & $97 \%$ & $100 \%$ & $100 \%$ & $100 \%$ & $99 \%$ & $94 \%$ & $100 \%$ & $90 \%$ \\
\hline
\end{tabular}

Apart from the simple comparison of percentages of correct quiz scores, several statistical analyses were performed on the pre and post-test data and the results were analyzed. One of the statistical analyses included a paired sample t-test conducted using the data from the 72 students who completed both the pre and post-tests to test if there was a significant difference in the performance of students before and after reviewing the tutorial. As it can be seen from the results indicated in Table 3, there was a significant difference $(p<0.05)$ at $95 \%$ confidence level for eight of the first twelve pre and post-test pairs compared. For two of the pairs (Q8 and Q10), the standard error of the difference was 0 . That is, the results were identical for those two questions for pre and post-tests, and so there was no point in comparing them.

TABLE III: RESULTS FROM THE PAIRED SAMPLES T-TEST

\begin{tabular}{|c|c|c|c|c|c|c|c|c|}
\hline \multirow{2}{*}{$\begin{array}{l}\text { Pairs of Pre Test - Post Test } \\
\text { Question }\end{array}$} & \multicolumn{7}{|c|}{ Paired Differences } & \multirow{2}{*}{$\begin{array}{l}\text { Sig. } \\
\text { (2-tailed) }\end{array}$} \\
\hline & Mean & Std. Dev & $\begin{array}{l}\text { Std. Error } \\
\text { Mean }\end{array}$ & \multicolumn{4}{|c|}{$\begin{array}{l}95 \% \text { Confidence Interval } \\
\text { on the Difference }\end{array}$} & \\
\hline Pair 1 Q1 - Q1 & -0.083 & 0.325 & 0.038 & -0.160 & -0.007 & -2.176 & 71 & 0.033 \\
\hline Pair 2 Q2 - Q2 & -0.125 & 0.442 & 0.052 & -0.229 & -0.021 & -2.399 & 71 & 0.019 \\
\hline Pair 3 Q3 - Q3 & -0.042 & 0.201 & 0.24 & -0.089 & 0.006 & -1.757 & 71 & 0.083 \\
\hline Pair 5 Q5 - Q5 & -0.111 & 0.491 & 0.058 & -0.226 & 0.004 & -1.920 & 71 & 0.059 \\
\hline Pair 6 Q6 - Q6 & 0.000 & 0.168 & 0.020 & -0.039 & 0.039 & 0.000 & 71 & 1.000 \\
\hline Pair 7 Q7 - Q7 & -0.056 & 0.285 & 0.034 & -0.123 & 0.011 & -1.653 & 71 & 0.103 \\
\hline Pair 9 Q9 - Q9 & -0.153 & 0.362 & 0.043 & -0.238 & -0.068 & -3.578 & 71 & 0.001 \\
\hline Pair 11 Q11 - Q11 & -0.139 & 0.387 & 0.046 & -0.230 & 0.048 & -3.048 & 71 & 0.003 \\
\hline Pair 12 Q12 - Q12 & -0.194 & 0.432 & 0.051 & -0.296 & -0.093 & -3.815 & 71 & 0.000 \\
\hline Pair 14 Q14 - Q14 & -0.319 & 0.526 & 0.062 & -0.443 & -0.196 & -5.152 & 71 & 0.000 \\
\hline Pair 15 Q15.1 - Q15.1 & -0.708 & 0.985 & 0.116 & -0.940 & -0.477 & -6.102 & 71 & 0.000 \\
\hline Pair 16 Q15.2 - Q15.2 & -0.847 & 1.070 & 0.126 & -1.099 & -0.596 & -6.717 & 71 & 0.000 \\
\hline Pair 17 Q15.3 - Q15.3 & -1.083 & 1.184 & 0.140 & -1.362 & -0.805 & -7.765 & 71 & 0.000 \\
\hline Pair 18 Q15.4 - Q15.4 & -1.319 & 1.555 & 0.183 & -1.685 & -0.954 & -7.200 & 71 & 0.000 \\
\hline Pair 19 Q15.5 - Q15.5 & -1.514 & 1.529 & 0.180 & -1.873 & -1.155 & -8.401 & 71 & 0.000 \\
\hline Pair 20 Q15.6 - Q15.6 & -1.375 & 1.605 & 0.189 & -1.752 & -0.998 & -7.270 & 71 & 0.000 \\
\hline Pair 21 Q15.7 - Q15.7 & -1.278 & 1.503 & 0.177 & -1.631 & -0.925 & -7.213 & 71 & 0.000 \\
\hline Pair 22 Q15.8 - Q15.8 & -1.708 & 1.748 & 0.206 & -2.119 & -1.298 & -8.294 & 71 & 0.000 \\
\hline Pair 23 Q15.9 - Q15.9 & -1.375 & 1.560 & 0.184 & -1.742 & -1.008 & -7.477 & 71 & 0.000 \\
\hline Pair 24 Q15.10 - Q15.10 & -1.542 & 1.846 & 0.218 & -1.975 & -1.108 & -7.087 & 71 & 0.000 \\
\hline
\end{tabular}

However, the eight of the twelve questions compared confirmed that the students performed better after reviewing the tutorial. The other two questions were not significant at $p<0.05$, which can be attributed to any number of factors including that the tutorial content related to those questions was easy to comprehend without the tutorial. Paired samples t-test was also conducted to compare scores from the 15th question which was a self-rating question by students. The 15th question had 10 items, with a Likert scale for each question, for a total of 24 test questions in the pre and post-tests. The paired samples t test of these 10 items showed that there was a significant difference between pre and post test scores at $95 \%$ confidence, indicating students rated themselves higher after reviewing the module.

\section{CONCLUSIONS}


It is critical that educational institutions are on the forefront of addressing academic integrity so that students recognize the long-term consequences of academic dishonesty for themselves and then for their employers as well as the society. It is difficult to enforce or police integrity but the best approach is to increase one's awareness of integrity. A self-paced, online tutorial on academic integrity is one of the best ways to engage students to reflect on academic integrity at their own pace and without any scrutiny. The implemented tutorials are being used by faculty and students not only at Northern Illinois University but also at other universities. The tutorials are freely accessible and usable by anyone, and to date more than 100,000 users have visited the tutorial site from over 125 countries, and the student tutorial has also been translated into Spanish by a university in Chile.

Designing and making tutorials available to students and faculty is only one part of the effort in addressing academic integrity, and more needs to be done regularly to promote academic integrity. Students have to be reminded periodically about the importance of academic integrity and faculty should continue to monitor students' work for cheating and plagiarism. At Northern Illinois University, some faculty require their students to review the tutorial every semester and submit the Certificate of Completion to remind students continually about academic integrity. New students, especially international students and non-native speakers, may need orientation on how to protect themselves from false accusations of academic dishonesty due to cultural misunderstanding and differences in intellectual property rights among countries.

Along with students, faculty also need guidance on issues related to students' academic dishonesty and how courses and course activities can be designed better to prevent academic dishonesty. Faculty need to move from punitive to proactive approaches [18]. Writing-infused courses that promote good writing skills can help students prevent plagiarism. It is important for faculty to serve as role models for students by demonstrating in their teaching materials as well as in scholarly publications proper citation of external sources. It is imperative that faculty continuously educate themselves on current technologies so that they can prevent students from using technologies to engage in academic dishonesty. In addition to establishing policies and procedures for handling academic dishonesty incidents, institutions should also license cheating and plagiarism detection tools to support faculty in assisting students to prevent academic dishonesty.

The efforts by educational institutions to address academic integrity can lead to countries and corporations doing the same in the long run to curb industrial espionage and theft of intellectual property. An educational foundation on academic integrity provided through online tools and effective pedagogical techniques, and concerted effort by faculty and academic institutions are essential for promoting innovation in the long run.

\section{ACKNOWLEDGMENT}

The authors thank the Committee for the Improvement of Undergraduate Education at Northern Illinois University for its partial funding of this effort through the "Project for Improvement of Undergraduate Education" grant, the Faculty Development and Instructional Design Center for its additional funding for this project, and the Office of the Ombudsperson and University Writing Center for their contributions of this effort. The authors also thank Greg Barker of the Office of Testing Services at Northern Illinois University for his assistance with the analysis of results from this project, and the staff of Faculty Development and Instructional Design Center for their assistance with the implementation of the student as well as the faculty tutorials.

\section{REFERENCES}

[1] A. Bushway and W. R. Nash, "School cheating behavior," Review of Educational Research, vol. 47, no. 4, Autumn 1977.

[2] D. L. R. Jones, "Academic dishonesty: Are more students cheating?" Business Communication Quarterly, vol. 74, no. 2, pp. 141-150, Jun. 2011.

[3] J. Deranek and C. Parnther, "Academic honesty and the new technological frontier," The Hilltop Review, vol. 8, no. 1, article 4, 2015.

[4] N. W. Pino and W. L. Smith, "College students and academic dishonesty," College Student Journal, vol. 37, no. 4, pp. 490-500, 1993.

[5] A. Friedman, I. Blau, and Y. Eshet-Alkalai, "Cheating and feeling honest: Committing and punishing analog versus digital academic dishonesty behaviors in higher education," Interdisciplinary Journal of $e$-Skills and Life Long Learning, vol. 12, pp. 193-205, 2016.

[6] B. E. Whitley and P. Keith-Spiegel, Academic Dishonesty: An Educators Guide, Mahwah, NJ: Lawrence Erlbaum Associates, 2002.

[7] B. S. Brown and D. Emmett, "Explaining variations in the level of academic dishonesty in studies of college students: Some new evidence," College Student Journal, vol. 34, no. 4, 2001.

[8] R. L. Sims, "The relationship between academic dishonesty and unethical business practices," Journal of Education for Business, vol. 68, no. 4, pp. 207-211, 1993.

[9] D. D. Carpenter, T. S. Harding, C. J. Finelli, and H. S. Pasow, "Does academic dishonesty relate to unethical behavior in professional practice? An exploratory study," Science and Engineering Ethics, vol. 10, no. 2, pp. 311-324, 2004.

[10] R. A. Kahn, "Economic espionage in 2017 and beyond: 10 shocking ways they are stealing your intellectual property and corporate mojo," Business Law Today.

[11] R. A. Oppel and K. Eichenwald, "ENRON's collapse: The observer; Arthur Andersen fires an executive for ENRON orders," The New York Times, Jan. 16, 2002.

[12] Asia Pacific Forum on Educational Integrity. [Online]. Available: http://www.apfei.edu.au

[13] J. Meade, "Cheating: Is academic dishonesty par for the course?" Prism, vol. 1 , no. 7, pp. 30-32, 1992.

[14] D. Simpson, "Academic dishonesty: An international student perspective," Academic Perspectives in Higher Education, vol. 2, no. 5, 2016.

[15] L. W. Thompson, J. H. Bagby, T. N. Sulak, J. Sheets, and T. M. Trepinski, "The cultural elements of academic honesty," Journal of International Students, vol. 7, no. 1, pp. 136-153, 2017.

[16] SafeAssign. Use SafeAssign in Assignments. Blackboard, Inc. [Online]. Available: http://help.blackboard.com/Learn/Instructor/Assignments/SafeAssign

[17] M. Krishnamurthi and J. Rhode, "Promoting academic integrity through an online module," presented at 2006 AASE Annual Conference \& Exposition, Chicago, IL, June 18, 2006.

[18] A. P. P. Babb, L. Yeworiew, and S. Sabbaghan, Selected Proceedings of the IDEAS Conference 2017: Leading Educational Change, Canada: Werklund School of Education, University of Calgary.

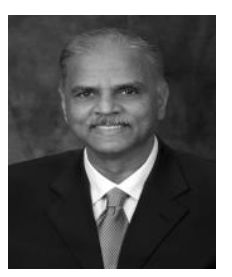

Murali Krishnamurthi received a bachelor's degree in mechanical engineering in 1978 from University of Madras, a master's degree in industrial and systems engineering in 1982 from Ohio University, and a doctorate in industrial engineering in 1988 from Texas A\&M University.

$\mathrm{He}$ is a professor of industrial and systems engineering and vice provost for faculty affairs at 
Northern Illinois University in DeKalb, Illinois, USA. His teaching and research interests include project management, information systems, system simulation, optimization techniques, faculty development, and distance learning.

Dr. Krishnamurthi received the Faculty of the Year Award for Excellence in in Undergraduate Education for 1994 and 1997 from the College of Engineering and Engineering Technology, and the Presidential Teaching Professor Award and the Deacon Davis Diversity Award for 2011 at Northern Illinois University.

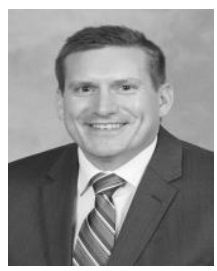

Jason Rhode received his bachelor's degree in children's ministries in 2000 from North Central University, a master's degree in curriculum and instruction in 2003 from Seattle Pacific University, and a doctorate in instructional design for online learning from Capella University in 2008.

$\mathrm{He}$ is an assistant professor of instructional technology and director of the Faculty Development and Instructional Design Center at Northern Illinois University in DeKalb, Illinois, USA. His research interests include online teaching and learning, instructional design, faculty development, learning management systems, and distance learning administration.

Dr. Rhode is a member of the Professional and Organizational Development (POD) Network, Online Learning Consortium, and the University Professional and Continuing Education Association. He has received numerous online teaching awards, including the recent 2016 Blackboard Catalyst Award for Exemplary Course Design and was named one of Top 30 Technologists, Transformers and Trailblazers for 2016 by the Center for Digital Education. His is also a recipient of the 2012 Supportive Professional Staff Presidential Award for Excellence and 2016 Award for Excellence in Supervision at Northern Illinois University. 